\title{
ALGUNAS NOTAS SOBRE LA RESOLUCIÓN POR INCUMPLIMIENTO A partir de la sentencia de la Corte Suprema de fecha 27 de SEPTIEMBRE DE 2016 ("INELCO CON SAESA")
}

\section{Notes ABOUt RESCISSION Of CONTRACT FROM the SUPREME COURT'S RULING of SePteMBER 27th, 2016 ("INELCO v. SAESA")}

Branco Andrés Aravena Cuevas* Trabajo recibido el 24 de noviembre de 2018 y aprobado el 3 de junio de 2019

\section{Resumen}

El presente comentario busca destacar, con ocasión de la sentencia analizada, algunos aspectos relevantes del remedio denominado resolución por incumplimiento. De este modo, nos referiremos a la finalidad de este mecanismo, cuestión común que comparte con los otros remedios contractuales, esto es, satisfacer el interés o propósito práctico del acreedor, frustrado por el incumplimiento del deudor, y que -en particular- consiste en deshacer el contrato a fin de buscar una operación de reemplazo en el mercado; acto seguido, abordaremos lo relativo al ejercicio unilateral y extrajudicial de este remedio, para luego examinar la redacción de la estipulación objeto del fallo, así como la entidad del incumplimiento resolutorio, asumiendo como punto de partida que la forma más idónea de modular el ejercicio y eficacia de este remedio es a través de una cláusula resolutoria. Finalmente, ofreceremos algunas conclusiones.

Palabras clave: resolución por incumplimiento, propósito práctico, ejercicio unilateral y extrajudicial del remedio, entidad del incumplimiento, cláusula resolutoria.

\begin{abstract}
This comment aims to highlight, from the analyzed ruling, some relevant aspects of the remedy called rescission of contract. In this way, we will refer about the purpose of this mechanism, a common aspect that it shares with other contractual remedies, that is, to satisfy the interest or practical purpose of the creditor, frustrated by the debtor's default, and that, in particular, consists in unmake the contract in order to seek a replacement in the market. Afterwards, we will attend to what concerns the unilateral and extrajudicial exercise of this remedy, to then examine the wording of the stipulation, as well as the seriousness of the breach of contract, assuming as a starting point that the best way to regulate the exercise and efficacy of this remedy is through a resolutory clause. Finally, we will offer some conclusions.
\end{abstract}

Keywords: rescission of contract, practical purpose, unilateral and extrajudicial exercise of the remedy, seriousness of the breach of contract, resolutory clause.

\footnotetext{
Branco Andrés Aravena Cuevas. Abogado, Licenciado en Ciencias Jurídicas de la Universidad de Valparaíso. Diplomado en Derecho de Contratos por la Pontificia U. Católica de Valparaíso. Estudiante de Magíster en Derecho, mención Derecho Civil, de la Pontificia U. Católica de Valparaíso. Correo de contacto: branco.aravenacuevas@gmail.com.
} 


\section{LA SENTENCIA ${ }^{1}:$ HECHOS Y RESOLUCIÓN.}

Entre las partes mediaban ciertos contratos por los cuales INELCO se adjudicó cuatro proyectos, en cuya virtud se obligó a la instalación de servicios eléctricos en determinados inmuebles. Luego, el 3 de febrero de 2012, SAESA comunicó al primero su intención de no continuar con los servicios, debido a sus reiterados incumplimientos.

No obstante lo anterior, INELCO dedujo demanda de resolución de contrato y, en subsidio, de cumplimiento específico, ambas con indemnización de perjuicios, en contra de SAESA, fundadas en los supuestos incumplimientos de esta última, tales como la falta de claridad al planificar los trabajos, la demora perjudicial en la entrega de planos, la falta culpable de tramitación de permisos o cambios de obras, entre otros.

SAESA, por su parte, solicitó el rechazo de ambas pretensiones en razón de no haber incumplido sus obligaciones, sumado a que ya había comunicado a INELCO la decisión de dar fin a sus servicios, por lo que no había contratos que resolver ni hacer cumplir, lo que se justificaba en el anexo denominado "condiciones generales", documento que integraba los contratos que vinculaban a las partes, en que se le facultaba para poner término a éstos de forma anticipada, ipso facto y unilateralmente en caso que INELCO incumpliera cualquiera de las obligaciones que eran de su cargo. A mayor abundamiento, SAESA demandó reconvencionalmente indemnización de perjuicios, argumentando que la inobservancia de INELCO le obligó a asumir los costos y ejecución de las obras inconclusas, las que presentaban serias falencias técnicas (considerando $\left.6^{\circ}\right)^{2}$.

En primera instancia fueron rechazadas ambas pretensiones del demandante principal, y se dio lugar a la demanda reconvencional de indemnización de perjuicios. En segunda instancia, la Corte de Apelaciones de Valdivia confirmó lo resuelto por el tribunal a quo. Por último, la Corte Suprema rechazó el recurso de casación en el fondo intentado por INELCO, el que se sustentó en los siguientes capítulos: (1) la infracción a las leyes reguladoras de la prueba; y (2) que el pacto comisorio calificado requería de pronunciamiento judicial, en virtud de causa legal.

En cuanto al primer capítulo, baste decir que la Corte Suprema lo descartó, ya que lo relativo a la apreciación de la prueba testimonial -de acuerdo con lo disciplinado en el artículo 384 del Código de Procedimiento Civil-, así como la ponderación comparativa de medios de prueba agregados al proceso, ex artículos 428 y 429 del mismo cuerpo normativo, escapan a su control (considerando $8^{\circ}$ ). Respecto del segundo capítulo, que es el que nos convoca, el Tribunal discurrió sobre las siguientes premisas: que el Código Civil reconoce la condición resolutoria tácita en su artículo 1489, cuyo hecho constitutivo es la infracción de una de las obligaciones de las partes, siendo una norma legal destinada a proteger el cumplimiento de aquella parte que cumple (sic) para exigir a la otra lo mismo, resolviéndose el contrato

\footnotetext{
1 Ingeniería Eléctrica y Construcción Ltda. (INELCO) con Sociedad Austral de Electricidad S.A. (SAESA) (2016). Resolución por incumplimiento, cumplimiento específico e indemnización de perjuicios.

2 "SEXTO. Que en el caso sublite son hechos establecidos por los jueces del fondo, los siguientes:

a).- Que SAESA no incurrió en incumplimiento culpable o doloso de las obligaciones que le imponían los contratos suscritos por las partes.

b).- Que INELCO incurrió en incumplimiento de las obligaciones, toda vez que: 1) respecto del contrato Terminal de Buses de Puerto Montt ejecutó menos obras que las pagadas; 2) en el Conjunto Residencial Osorno incurrió en atrasos y tampoco terminó completamente las obras; y 3) en el Mall de Castro y Conjunto Residencial Osorno incurrió en insuficiencia y ausencia de personal.

c).- Que SAESA terminó los contratos el 3 de febrero de 2012, decisión anticipada a INELCO por carta y aceptada por ésta".
} 
si ese fin principal no pudiere conseguirse (considerandos $5^{\circ}$ y $\left.11^{\circ}\right)^{3-4}$. Acto seguido, previo análisis del panorama normativo del pacto comisorio calificado, concluye que éste puede establecerse fuera del caso previsto por el legislador ${ }^{5}$, cuya justificación reside en el principio de libertad contractual (considerando $\left.12^{\circ}\right)^{6}$. Finalmente, asumiendo que los contratantes pueden acogerse a uno u otro régimen, según lo estimen conveniente (considerando $\left.13^{\circ}\right)^{7}$, lo cierto es que el anexo denominado "condiciones generales" preveía en favor de SAESA -ante cualquier incumplimiento de las obligaciones de cargo de INELCO- la facultad de dar término anticipado, ipso facto y de forma unilateral a los contratos, siendo efectivo que el recurrente de casación en el fondo los infringió, lo que llevó a la empresa mandante a comunicar su intención de terminarlos, sumado a que no corresponde judicializar el pacto comisorio calificado, cuestión

3 "QUINTO. Que en el contexto de la controversia sub lite, en primer lugar resulta pertinente recordar que la condición resolutoria tácita surge del texto del artículo 1489 del Código Civil. Se ha entendido que este precepto envuelve una regla que rige exclusivamente la situación que se produce en los contratos bilaterales cuando una de las partes ha cumplido o está llana a cumplir el contrato y la otra se niega a hacerlo.

Para que opere la acción resolutoria deben concurrir los siguientes supuestos: a) que se trate de un contrato bilateral, b) que las obligaciones estén pendientes en la época de su resolución, c) que no se cumpla por una de las partes lo pactado, y d) que el contratante que pide la resolución debe haber cumplido por su parte o debe estar llano a cumplir en tiempo y forma.

La disposición en estudio se encarga de disponer la resolución de todo contrato bilateral en que una de las partes 'cumplidora o Ilana a cumplir'se enfrenta a un co-contratante que no hace lo propio. Es una norma legal destinada a proteger el cumplimiento de aquella parte que cumple para exigir de la otra lo mismo, resolviéndose el contrato si ese fin principal no pudiere conseguirse". 4 "UNDÉCIMO. Que nuestro Código Civil establece la condición resolutoria tácita en relación con los contratos bilaterales, como se desprende del tenor literal del artículo 1489, que dice lo siguiente: 'En los contratos bilaterales va envuelta la condición resolutoria de no cumplirse por uno de los contratantes lo pactado. Pero en tal caso podrá el otro contratante pedir a su arbitrio o la resolución o el cumplimiento del contrato con indemnización de perjuicios'.

Tal como ya se anunciara, el hecho constitutivo de la condición resolutoria tácita es la infracción de una obligación por una de las partes, lo que significa que si ese hecho se produce, la condición se cumple. En consecuencia, frente al incumplimiento de una de las partes el contratante diligente puede ejercer la acción resolutoria que contempla el artículo 1489 ya citado".

5 A propósito del fallo en comento, la doctrina ha destacado que tiene la virtud de reconocer que las partes pueden estipular pactos comisorios calificados atípicos. En este sentido: Cárdenas y Reveco (2018), pp. 330-331.

6 "DUODÉCIMO. Que, sin perjuicio de lo anterior, el Código Civil reglamenta en los artículos 1877 a 1880 el pacto comisorio como una convención accesoria al contrato de compraventa, en virtud de la cual las partes estipulan que el incumplimiento de la obligación del comprador de pagar el precio traerá como consecuencia la resolución del contrato. Este pacto regulado por la ley es conocido como el pacto comisorio típico.

Las normas del pacto comisorio no prevén una convención similar referida al incumplimiento de otras obligaciones distintas de la que contrae el comprador de pagar el precio. El Código Civil tampoco contempla esta convención en otros contratos, lo que ha llevado a la doctrina y jurisprudencia a preguntarse si es legalmente posible la estipulación de un pacto comisorio que no coincida con el regulado por la ley.

Sobre este punto el profesor V.V. del R. sostiene que'si bien es cierto que el legislador solamente reglamenta el pacto comisorio típico e ignora la existencia de convenciones similares que no coincidan con la descrita en los artículos antes citados, no prohíbe su estipulación. En consecuencia, y aplicando el principio de la libertad contractual, la doctrina acepta la estipulación de pactos comisorios atípicos; ello, porque los contratantes pueden crear figuras jurídicas que no coincidan con las previstas por el legislador, a menos que atenten contra la ley, la moral, las buenas costumbres o el orden público' (Manual de las Obligaciones en el Código Civil Chileno, 2Edición, Editorial Biblioteca Americana, año 2007, página 77)".

7 "DÉCIMOTERCERO. Que, en tal sentido, existe por parte de la doctrina un reconocimiento en cuanto a que el pacto comisorio calificado puede establecerse en otros contratos. Esta convención ha sido llamada como pacto comisorio atípico, a diferencia del regulado en la compraventa por el incumplimiento de la obligación del comprador de pagar el precio.

Se ha entendido entonces que en ausencia de una norma legal que determine los efectos del pacto comisorio atípico, se debe atender a la intención de las partes con su estipulación. En efecto, las partes pueden querer que se produzcan los efectos de la condición resolutoria tácita, lo que supone una sentencia judicial que declare el contrato resuelto como consecuencia del ejercicio de la acción resolutoria o, por el contrario, que los efectos se produzcan de pleno derecho. En consecuencia, las palabras utilizadas por las partes van a constituir un elemento importante para conocer su intención.

En la práctica, lo usual es la estipulación de un pacto comisorio que produzca de pleno derecho la resolución del contrato, específicamente, cuando se estima que la infracción de una determinada obligación hace que el contrato pierda el sentido para el cual fue convenido y, por lo tanto, deja de constituir el medio idóneo para satisfacer legítimos intereses. Resulta entonces necesario que del solo tenor literal del contrato se desprenda claramente la intención de que este se extinga sin necesidad de sentencia judicial, por el solo hecho de verificarse la infracción de obligación". 
que repugnaría con lo acordado por las partes (considerandos $14^{\circ}$ y $\left.15^{\circ}\right)^{8-9}$.

\section{Comentarios}

Con ocasión del fallo en estudio trataremos los siguientes tres puntos: (1) la función de la resolución por incumplimiento; (2) el ejercicio unilateral y extrajudicial del remedio; y (3) la redacción de la cláusula del caso en comento y, en particular, lo concerniente a la entidad del incumplimiento resolutorio. Por último, cerraremos este trabajo con unos comentarios finales.

\subsection{La función de la resolución por incumplimiento}

Anotemos, en primer lugar, que de la sentencia se desprende que es posible predicar de la resolución por incumplimiento lo siguiente: que la condición resolutoria tácita "(...) envuelve una regla que rige exclusivamente la situación que se produce en los contratos bilaterales cuando una de las partes ha cumplido o está llana a cumplir el contrato y la otra se niega a hacerlo", a la par que sería "una norma legal destinada a proteger el cumplimiento de aquella parte que cumple (sic) para exigir de la otra lo mismo, resolviéndose el contrato si ese fin principal no pudiere conseguirse"10. Más adelante, en la parte final del considerando $13^{\circ}$, se expresa que el pacto comisorio calificado opera cuando "se estima que la infracción de una determinada obligación hace que el contrato pierda el sentido para el cual fue convenido y, por lo tanto, deja de constituir el medio idóneo para satisfacer legítimos intereses". Así las cosas, la sentencia objeto de este trabajo -por un lado- se equivoca, pero acierta por el otro. Pasemos a analizar.

Es sabido que nuestra jurisprudencia ha extrapolado erróneamente ${ }^{11}$ el supuesto de la compensación

8 "DÉCIMO CUARTO. Que, como se ha venido analizando, el principio de la libertad contractual permite que los contratantes expresamente estipulen que la sanción al incumplimiento del contrato será la resolución del mismo, sin necesidad de declaración judicial. De esta forma, nada impide a las partes establecer una cláusula resolutoria expresa con independencia de la normativa aplicable al incumplimiento del pago del precio en la compraventa, como también determinar que dicho pacto operará sin intervención judicial. En otras palabras, el pacto comisorio calificado podrá producir un efecto resolutorio sin intervención judicial si los contratantes lo estipularon expresamente, de manera que el contratante diligente no requerirá intervención judicial frente al incumplimiento del otro".

9 "DÉCIMO QUINTO. Que del análisis del anexo 'Condiciones Generales', que forma parte integrante de cada uno de los contratos suscritos por las partes, se aprecia que estas expresamente contemplaron la facultad de poner término anticipado, ipso facto y unilateralmente al contrato ante cualquier incumplimiento de las obligaciones que eran de cargo de INELCO.

Es decir, los contratantes expresamente establecieron la procedencia del pacto comisorio calificado, sin necesidad de declaración judicial previa, de manera que se debe estar a esa manifestación de voluntad, la que no puede ser desconocida por ninguna de las partes que la suscribieron. Luego, siendo un hecho establecido en la causa que INELCO incumplió sus obligaciones al no emplear la debida diligencia y cuidado en la ejecución de las obras encomendadas, la demandada principal y demandante reconvencional se encontraba facultada para poner término a la relación contractual que la vinculaba con la contraria, resultando para ello suficiente la comunicación efectuada mediante carta, sin que sea exigible en la especie, dado los términos del pacto comisorio calificado, accionar ante el órgano jurisdiccional con el fin de perseguir que éste declare la resolución de los contratos. Judicializar el pacto comisorio calificado repugna a la esencia de este pacto, afectando con ello el principio de la libertad contractual, toda vez que si las partes acordaron que el incumplimiento acarrea la resolución de pleno derecho debe respetarse la voluntad expresada en el contrato, puesto que si hubieren querido otra cosa lo habrían especificado, salvo en aquellos casos en que exista un interés superior comprometido, o se afecte el orden público, la moral o las buenas costumbres, lo que no ocurre en la especie".

10 Considerando $5^{\circ}$.

11 El error, desde luego, se aprecia desde el prisma del moderno Derecho de los contratos, el que establece como una de sus premisas fundamentales que el incumplimiento se entiende como cualquier desviación del programa contractual, de carácter unitario y objetivo, lo que lleva -a su turno- a asumir que el remedio resolutorio sólo precisa de un incumplimiento esencial o grave, abandonando otras exigencias, tales como (a propósito de la sentencia en estudio) las de haber un contratante diligente y otro negligente. Véase: Vidal (2009), pp. 221-233.

ARAVENA CUEVAS, Branco Andrés. Algunas notas sobre la resolución por incumplimiento a partir de la sentencia de la Corte Suprema de fecha 27 de septiembre de 2016 ("INELCO con SAESA"). Revista Justicia y Derecho, Santiago, v. 2, n 1, 2019 
en mora y de la excepción de contrato no cumplido a los remedios contractuales, y muy particularmente a la resolución. Ahora, sin perjuicio de la discusión acerca de si el artículo 1552 del Código Civil consagra o no la exceptio non adimpleti contractus, tanto la compensación en mora como la excepción referida"son manifestaciones del principio de simultaneidad en el cumplimiento de las obligaciones y cuyos efectos se verifican: si uno de los contratantes no cumple o no se encuentra llano a hacerlo"12, lo que inclina a sostener que ambas figuras cumplen la función de atajar pretensiones del acreedor, sea que se busque frenar el mecanismo de cumplimiento ${ }^{13}$-haciéndose valer el conocido "pasando y pasando"14-, o bien, para librarse del remedio indemnizatorio, según sea el caso.

No obstante lo anterior, este fallo va más allá, puesto que no sólo le atribuye a la resolución el requisito propio de las instituciones recién señaladas, sino que deja al remedio resolutorio en una zona gris, por cuanto le asigna como función la posibilidad de exigir de la otra parte la prestación debida, cual pretensión de cumplimiento específico ${ }^{15}$, distorsionando - de este modo- el efecto que le es propio. Por lo demás, razonar de la forma en que se sugiere en el considerando $5^{\circ}$ significaría que el acreedor, al ejercer el remedio resolutorio, buscaría -en principio- que el deudor cumpla, y luego, en caso de no ser alcanzado este objetivo, que el contrato se resuelva.

Es necesario precisar que la resolución por incumplimiento, tal como parece describirla la Corte Suprema en el considerando $5^{\circ}$ de la sentencia en estudio, funcionaría como una suerte de amenaza para el deudor incumplidor en orden a que satisfaga el interés contractual del acreedor, bajo apercibimiento de que se deshaga el contrato; y lo cierto es que si el acreedor decide resolver es, naturalmente, porque ya no persigue la contraprestación del deudor. Debemos recordar a este respecto que la elección del remedio contractual le compete al acreedor, en la medida que haya incumplimiento, que se verifiquen los especiales supuestos del mecanismo en cuestión -la esencialidad o gravedad del incumplimiento en el caso de la resolución-y, finalmente, que el remedio sea gestionado razonablemente y de buena fe por el acreedor insatisfecho.

Ahora, a pesar del desacierto expuesto arriba, la Corte Suprema da en el blanco al declarar que las partes -con ocasión del incumplimiento de un contrato- pueden estimar que el negocio ha perdido el sentido para el cual fue convenido, por lo que éste ya no sirve para lograr la consecución del interés contractual tutelado. De esta manera, el fallo tiene la virtud de reconocer lo que es la finalidad económico-realista del contrato ${ }^{16}$, que permite comprender a este último ya no solamente desde una concepción puramente jurídica, que entendía al contrato como una simple convención creadora de derechos personales y obligaciones ${ }^{17}$, sino que esencialmente como un instrumento de distribución de riesgos y de satisfacción de intereses prácticos. En este sentido, "las partes, al contratar, buscan la consecución de un propósito práctico que alcanzarán a través de la ejecución del contrato, propósito que interesa en la medida que se hubiere incorporado -explícita o implícitamente- a la regla contractual"18. Este propósito práctico incorporado al contrato y tutelado por éste se denomina interés contractual ${ }^{19}$.

Pues bien, cuando el acreedor ve insatisfecho su interés contractual, puede servirse de los distintos mecanismos que integran el abanico de remedios contractuales, entre los que se encuentra la resolución

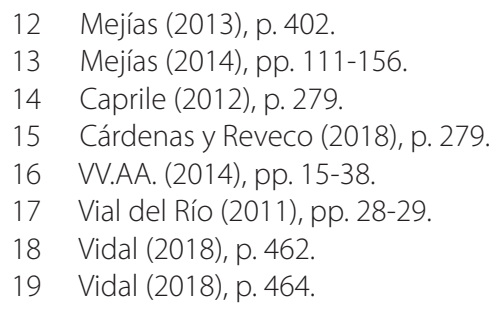


por incumplimiento, cuyo propósito es permitir que aquel se desentienda del negocio que lo vinculaba con el deudor, y acudir al mercado -nuevamente- a fin de buscar una operación que resulte adecuada y que pueda reemplazar aquella que se ha visto frustrada a causa de la inobservancia de su co-contratante ${ }^{20}$.

\subsection{El ejercicio unilateral y extrajudicial del remedio resolutorio}

Es aceptado tanto en la sentencia como por nuestra doctrina ${ }^{21}$ que el remedio resolutorio puede ejercerse fuera de tribunales. En este orden de cosas, y a propósito de lo previsto en el artículo 1489 del Código Civil, se ha dicho que en esta norma hay una invitación a que sea modificada por las partes -bajo la idea de que la resolución por incumplimiento regulada en esta disposición es un elemento de la naturaleza ${ }^{22}$ de los contratos bilaterales-; y esta invitación se ajusta precisamente a las necesidades del tráfico jurídico ${ }^{23}$, toda vez que, ante el incumplimiento del contrato, no es razonable que el acreedor insatisfecho permanezca vinculado a un deudor que, con su contravención, frustra el propósito práctico protegido por el negocio. De este modo, siendo la condición resolutoria tácita un elemento de la naturaleza, perfectamente puede ser prescindida y reemplazada ${ }^{24}$ por una cláusula resolutoria que prevea el incumplimiento que dará lugar al ejercicio de la facultad que llevará el contrato a su fin y el procedimiento para ponerla en práctica.

Ahora, a propósito del caso en estudio, lo cierto es que resulta interesante la forma en que SAESA ejercitó el remedio resolutorio. Podemos coincidir en que su aplicación fue unilateral y extrajudicial, empero, queda la pregunta acerca del momento en que se produce la resolución. Y nos preguntamos esto ya que -según se sigue del fallo- las partes estipularon un pacto comisorio calificado atípico ${ }^{25}$, lo que no resulta sorprendente, pero lo que sí llama la atención es que, a pesar de las palabras empleadas en la estipulación respectiva, es decir, que se facultaba a SAESA para poner término anticipado, ipso facto y unilateralmente al contrato frente a cualquier incumplimiento, la resolución se produjo en virtud de una comunicación que SAESA envió a INELCO, y que este último aceptó. Entonces, ¿de qué forma cobró eficacia la resolución?

Pareciera ser que las partes, a pesar del tenor del contrato, dieron una aplicación distinta al pacto comisorio calificado -lo que se puede solucionar interpretativamente por medio de lo dispuesto en el artículo 1564 del Código Civil26-, esto es, que en vez haberse resuelto de pleno derecho el negocio, se procedió por medio de un acto recepticio, lo que se adecua - de mejor forma- a las exigencias del tráfico y a la certeza que éste requiere.

Lo anterior, por cierto, da cuenta de un vacío existente en nuestro Código Civil en lo que concierne

\footnotetext{
20 En este sentido: Peñailillo (2006), p. 395; Lyon (2017), p. 250.

21 Por todos: Pizarro (2012), p. 363.

22 Lyon (2017), p. 247.

23 Pizarro (2012), p. 359.

24 El modelo de ejercicio judicial del remedio resolutorio genera dos inconvenientes: por un lado, la actual configuración del procedimiento civil implica un largo tiempo de tramitación, y por otro, si es el juez quien debe determinar la entidad del incumplimiento, las partes no pueden anticipar si éste será calificado o no como esencial o grave. Por consiguiente, en aquellos casos en que las partes perfilan contractualmente los incumplimientos que tendrán trascendencia resolutoria, lo que hacen es indicarse a sí mismas cuándo se podrá ejercer este mecanismo, y cuándo no, logrando distribuir adecuadamente el riesgo del incumplimiento.

25 Si es que acaso la cláusula en revisión puede ser considerada como un verdadero pacto comisorio calificado atípico, en razón de su defectuosa formulación y puesta en práctica.

26 López Santa María (2010), p.401.
}

ARAVENA CUEVAS, Branco Andrés. Algunas notas sobre la resolución por incumplimiento a partir de la sentencia de la Corte Suprema de fecha 27 de septiembre de 2016 ("INELCO con SAESA"). Revista Justicia y Derecho, Santiago, v. 2, nº 1, 2019 
a la disciplina de la resolución extrajudicial en general, y de las cláusulas resolutorias en particular²7, lo que nos lleva, en orden a precisar cómo se puede perfilar la eficacia de la facultad resolutoria, a prestar atención a los mecanismos comparados en relación a este aspecto, como son, entre otros, los modelos establecidos en la Convención de Viena sobre compraventa internacional de mercaderías (CISG), en el reformado Código Civil de Francia y el nuevo Código Civil y Comercial de Argentina, y los Principios Latinoamericanos de Derecho de los Contratos, a los que nos referiremos brevemente.

En este orden de ideas, La CISG, en tanto que uno de los principales instrumentos de Derecho uniforme, habilita al acreedor a declarar la resolución del contrato, la que producirá sus efectos sólo si esta decisión es comunicada a la otra parte, de acuerdo con lo preceptuado en el artículo $26^{28}$, correspondiendo, en consecuencia, a un modelo de ejercicio del remedio resolutorio fuera de tribunales.

Por su parte, en lo tocante al Código Civil francés y al nuevo Código Civil y Comercial argentino, ambos coinciden en que la eficacia resolutoria se produce extrajudicialmente, sea por notificación ${ }^{29}$ o por comunicación ${ }^{30}$ dirigida al deudor, lo que es muestra de una desjudicialización del remedio contractual en estudio, y que se traduce en "en la eliminación del juez en la aplicación de las reglas del contrato"31.

Finalmente, el artículo 98 de los Principios Latinoamericanos de Derecho de los Contratos disciplina, a propósito de lo que venimos comentando, que: "la resolución opera mediante comunicación escrita a la otra parte y produce sus efectos desde su recepción" ${ }^{\prime \prime 2}$, disposición que tiene una doble virtud; por un lado, explicita que la resolución se ejerce por medio de una comunicación escrita que debe ser enviada al otro contratante, y por otro, que la eficacia resolutoria se perfecciona una vez que la comunicación es recibida por el deudor incumplidor.

Lo reseñado deja en evidencia que la tendencia en Derecho comparado es que el ejercicio del remedio resolutorio se lleva a cabo de forma extrajudicial, y que cobra eficacia por medio de una comunicación dirigida a la otra parte, cuestión que si bien no se encuentra regulada en nuestro ordenamiento jurídico, sí se halla recogida por la práctica contractual en virtud de la estipulación de genuinas cláusulas resolutorias ${ }^{33}$.

27 Los profesores Vidal y De la Maza expresan que: "(...) en nuestro Código Civil no se reconocen, ni regulan, las cláusulas resolutorias o de resolución extrajudicial. Es por esta razón que preferimos abandonar la discusión acerca de la aplicación extensiva del pacto comisorio a otras obligaciones en la compraventa y a otros contratos bilaterales". De la Maza y Vidal (2018), p. 510. 28 "Artículo 26. La declaración de resolución del contrato surtirá efecto sólo si se comunica a la otra parte".

29 El artículo 1226 del Código Civil francés dispone que: "El acreedor podrá, por su cuenta y riesgo, resolver el contrato por vía de notificación. Excepto en casos de urgencia, previamente deberá requerir al deudor en mora que satisfaga su compromiso en un plazo razonable.

El requerimiento hará constar de forma manifiesta que a falta por el deudor de satisfacer su compromiso, el acreedor tendrá derecho a resolver el contrato.

Cuando el incumplimiento persista, el acreedor notificará al deudor la resolución del contrato y las razones que la motiven.

El deudor podrá en todo momento impugnar ante el juez la resolución. En tal caso el acreedor deberá probar la gravedad del incumplimiento".

30 El artículo 1086 del nuevo Código Civil y Comercial argentino disciplina lo que sigue: "Cláusula resolutoria expresa. Las partes pueden pactar expresamente que la resolución se produzca en caso de incumplimientos genéricos o específicos debidamente identificados. En este supuesto, la resolución surte efectos a partir que la parte interesada comunica a la incumplidora en forma fehaciente su voluntad de resolver".

31 Savaux (2016), p. 734.

32 W.AA. (2017), p. 68.

33 Cuando hablamos de genuinas cláusulas resolutorias nos referimos a aquellas en las que el remedio resolutorio es comprendido como una facultad para el acreedor, junto con determinar cuáles son los incumplimientos que tendrán trascendencia resolutoria, así como que el remedio cobrará eficacia por medio de una comunicación dirigida al deudor incumplidor. 


\subsection{Sobre la redacción de la cláusula del caso en comento y, en particular, lo concerniente a la entidad del incumplimiento resolutorio}

Teniendo presente lo expuesto en el apartado anterior, corresponde revisar lo relativo a la formulación de la cláusula en estudio, especialmente en lo que incumbe a la gravedad o esencialidad que debe revestir el incumplimiento del contrato para que tenga transcendencia resolutoria.

Recordemos, de acuerdo con el considerando $15^{\circ}$ del fallo en análisis, que:"se aprecia que estas expresamente contemplaron la facultad de poner término anticipado, ipso facto y unilateralmente al contrato ante cualquier incumplimiento de las obligaciones que eran de cargo de INELCO". Ahora, a fin de aportar más claridad, dividiremos el enunciado en dos partes: (1) en lo que refiere a la facultad de poner término anticipado, ipso facto y unilateralmente al contrato; y (2) lo tocante a que esta resolución procederá ante cualquier incumplimiento de las obligaciones.

La primera parte de la cláusula, vale decir, la facultad para terminar anticipada, ipso facto y unilateralmente el contrato, da cuenta de una defectuosa técnica de redacción contractual, por cuanto confunde dos modelos contrapuestos de eficacia resolutoria, como son el pacto comisorio calificado con la cláusula resolutoria, toda vez que en el mismo enunciado se establece que se faculta al acreedor a resolver ipso facto los contratos; y son contrapuestos porque el pacto comisorio calificado produce sus efectos de forma simultánea al incumplimiento grave del deudor, mientras que en el diseño de la cláusula resolutoria el incumplimiento esencial habilita al acreedor, si acaso lo prefiere, a resolver el contrato en virtud de una comunicación dirigida a la otra parte. Por consiguiente, en la cláusula resolutoria la eficacia del remedio queda entregada al acreedor; en cambio, en el pacto comisorio calificado queda -realmente- en manos del deudor, quien, con su conducta, puede decidir si subsiste o no el contrato ${ }^{34}$.

Así las cosas, y siguiendo lo sostenido en este trabajo, la estipulación en comento debería haber sido redactada como una genuina cláusula resolutoria, esto es, que se regulara claramente que el acreedor -en este caso SAESA- se encontraba facultado para resolver el contrato, formulación que resguarda de mejor forma los intereses del acreedor, quien sabe si ejercer o no este remedio, junto con que permite conocer razonablemente cuándo se producirá efectivamente la resolución.

Ahora, para examinar la segunda parte de la cláusula en estudio, es decir, que la resolución procederá ante cualquier incumplimiento de las obligaciones, es indispensable que nos pronunciemos sobre qué clase de inejecución reviste el potencial suficiente para provocar la resolución del contrato.

Señalemos, entonces, que el incumplimiento que da lugar a la resolución debe ser esencia ${ }^{35}$ o grave, de suerte que una desviación ínfima del contrato no bastará para dejarlo sin efecto. Así las cosas, se ha dicho que para determinar cuándo la infracción contractual tiene trascendencia resolutoria, es necesario -en primer lugar- atender a la voluntad de las partes, con una restricción: a propósito de esta forma de modular el incumplimiento resolutorio, conviene anotar que ésta se encuentra limitada por el principio de la buena fe objetiva, contenido en el artículo 1546 del Código Civil, por lo que no es dable omitir la especificación del incumplimiento resolutorio, o que todas las obligaciones del contrato revistan el carácter de esencial, o que la infracción de cualquier obligación permita resolver el contrato ${ }^{36}$; y a falta de acuerdo, el juez podrá recurrir a otros criterios para dilucidar la entidad de la inobservancia, siendo uno de ellos el que se conoce como objetivo, el que "se vincula con el interés del acreedor, el propósito práctico que pretendió satisfacer con la ejecución del contrato y la incidencia que el incumplimiento y sus consecuencias

34 De la Maza y Vidal (2018), p. 516

35 Vidal (2009), p. 237.

36 Mejías (2018), p. 47.

ARAVENA CUEVAS, Branco Andrés. Algunas notas sobre la resolución por incumplimiento a partir de la sentencia de la Corte Suprema de fecha 27 de septiembre de 2016 ("INELCO con SAESA"). Revista Justicia y Derecho, Santiago, v. 2, n 1, 2019 
producen en él"37; y el otro criterio, denominado subjetivo, que es aquel que "se vincula con la conducta desplegada por el deudor en la ejecución de la prestación que conduce a una pérdida de confianza del acreedor en su futuro cumplimiento"38.

Lo expuesto permite sostener, en consecuencia, que no cualquier incumplimiento habilita al acreedor a ejercitar la facultad resolutoria ${ }^{39}$. Lo contrario, esto es, afirmar que cualquier infracción puede dar lugar a la resolución, supone desnaturalizar el sentido de una cláusula resolutoria, que viene a perfilar la gravedad de aquellas contravenciones que sirven de fundamento a este remedio, sumado a que implicaría traspasar al deudor el riesgo de cada uno de los posibles incumplimientos, provocando así un significativo desequilibrio contractual ${ }^{40}$.

Pues bien, habiendo aclarado en qué casos el incumplimiento es grave o esencial, resulta que -a la luz de lo anotado- la estipulación en análisis nuevamente falla, por cuanto establece que, de forma indistinta, cualquier infracción dará lugar a la resolución, lo que nos lleva a sostener que si todo incumplimiento es grave, en realidad, ninguno lo es. En definitiva, cuando se redacta una cláusula en términos tan inespecíficos o difusos, lo que se hace es reiterar lo dispuesto en el artículo 1489 del Código Civil41, habilitando -por consiguiente- al juez a decidir si el incumplimiento denunciado tiene o no la entidad suficiente para poner fin al contrato. Lamentablemente, este punto no fue adecuadamente tratado por la Corte Suprema, que, en un análisis bastante superficial, se limitó a discurrir sobre la procedencia de un pacto comisorio calificado atípico y si para su aplicación es o no indispensable poner en movimiento al órgano jurisdiccional, junto con respaldar que cualquier incumplimiento permitía a SAESA resolver el contrato, de acuerdo con lo establecido en el anexo de "condiciones generales".

\section{Conclusiones}

De lo expuesto previamente podemos ofrecer los siguientes comentarios finales:

1. En primer lugar, el fallo en estudio nos permite recordar que el remedio resolutorio tiene como finalidad que el acreedor se desligue del deudor incumplidor y que pueda, en subsidio, buscar una operación de reemplazo que satisfaga su interés contractual. Este recordatorio fluye del error en que incurre la Corte Suprema al sobreponer los planos de la resolución por incumplimiento y de la compensación en mora y excepción de contrato no cumplido en cuanto al presupuesto de estas dos últimas figuras, junto con asignarle al remedio resolutorio los efectos propios del cumplimiento específico, lo que no se aviene con el fin del mecanismo de tutela en comento. Así las cosas, cuando el acreedor insatisfecho ejerce la facultad resolutoria, lo hace con miras a desvincularse del deudor incumplidor, y no a efectos de conminarlo a cumplir para que, en caso negativo, se resuelva efectivamente el negocio.

2. Se reafirma también la idea de que las partes son libres para regular convencionalmente el remedio resolutorio, indicando el procedimiento que se seguirá para ejercer la resolución,

\footnotetext{
37 Mejías (2011), p. 211.

38 Mejías (2011), p. 212.

39 Mejías (2011), p. 211.

40 Mejías (2011), pp. 222-223.

41 Pizarro (2012), p. 358.
} 
el momento preciso en que el contrato se entenderá resuelto, y si se ejercerá de forma extrajudicial, o bien, poniendo en movimiento al órgano jurisdiccional, sin perjuicio de que nos inclinamos por la idea de que se modulen genuinas cláusulas resolutorias y no pactos comisorios calificados, en razón de las desventajas prácticas que estos últimos conllevan.

3. Sin embargo, las partes no pueden prever que cualquier incumplimiento tenga trascendencia resolutoria, ya que el estándar que debe observarse es que precisas y determinadas infracciones contractuales revistan caracteres de esencialidad o gravedad (lo que será determinado por las partes, o bien, calificado por el juez, siguiendo los criterios señalados precedentemente). Esta exigencia permite garantizar la estabilidad del negocio, que las partes se comporten de buena fe, y lograr una apropiada distribución del riesgo del incumplimiento ${ }^{42}$.

4. Finalmente, para alcanzar una satisfactoria regulación del remedio resolutorio, se requiere una buena técnica de redacción contractual, a fin de evitar estipulaciones defectuosas que ocasionen más problemas que beneficios -como la de la sentencia en comento-, y que habiliten a los tribunales a inmiscuirse en el contrato, cuando lo que las partes buscaban era justamente lo contrario.

\section{Bibliografía Citada.}

Caprile Biermann, Bruno (2012): "Algunos problemas ofrecidos por la excepción de contrato no cumplido y, en especial, el de su invocación para atajar la acción resolutoria en el caso de incumplimiento recíproco de los contratantes", Revista de Derecho de la Pontificia U. Católica de Valparaíso, segundo semestre, pp. 53-93.

Cárdenas Villarreal, Hugo; Reveco Urzúa, Ricardo (2018): Remedios contractuales. Cláusulas, acciones y otros mecanismos de tutela del crédito (Chile, Editorial Legal Publishing).

De la Maza Gazmuri, Íñigo; Vidal Olivares, Álvaro (2018): Cuestiones de Derecho de Contratos. Formación, incumplimiento y remedios. Doctrina y jurisprudencia (Chile, Editorial Legal Publishing).

López Santa María, Jorge (2010): Los Contratos. Parte general (Chile, Editorial Legal Publishing).

Lyon Puelma, Alberto (2017): Integración, Interpretación y Cumplimiento de Contratos (Chile, Ediciones UC).

Mejías Alonzo, Claudia (2011): El incumplimiento resolutorio en el Código Civil (Chile, Editorial Legal Publishing).

Mejías Alonzo, Claudia (2013): "La excepción de contrato no cumplido y su consagración en el Código Civil chileno", Revista Chilena de Derecho, Vol. 40, № 2, pp. 389-412.

Mejías Alonzo, Claudia (2014): "La excepción de contrato no cumplido, un análisis de su aplicación en la jurisprudencia nacional reciente y en la doctrina", Revista de Derecho de la U. Católica del Norte, año 21, Nº 1, pp. 111-156.

42 La profesora Claudia Mejías, en orden a proponer los criterios para determinar cuál incumplimiento habilita al acreedor para resolver el contrato, considera los principios generales "de la preservación del contrato y el de la buena fe objetiva, conciliando los intereses en juego, el del acreedor y del deudor". Ver: Mejías (2011), p. 206. 
Mejías Alonzo, Claudia (2018): Resolución por incumplimiento: su procedencia y efectos (Chile, Cuadernos Jurídicos de la Academia Judicial, Der Ediciones).

Peñallillo Arévalo, Daniel (2006): Obligaciones. Teoría general y clasificaciones. La resolución por incumplimiento (Chile, Editorial Jurídica de Chile).

Pizarro Wilson, Carlos (2012): "Cláusula resolutoria y pacto comisorio calificado. Tan lejos tan cerca", en Estudios de Derecho Civil VIII (Chile, Editorial Legal Publishing) pp. 357-368.

Savaux, Éric (2016): "El nuevo Derecho francés de obligaciones y contratos", Anuario de Derecho Civil, España, Volumen LXIX, N III, pp. 715-741.

Vial del Río, Víctor (2011): Teoría General del Acto Jurídico (Chile, Editorial Jurídica de Chile, quinta edición).

Vidal Olivares, Álvaro (2009): "La noción de incumplimiento esencial en el 'Código Civil'", Revista de Derecho de la Pontificia U. Católica de Valparaíso, N XXXII, 1er Semestre, pp. 221-258.

VIDAL Olivares, Álvaro (2018): "La noción de incumplimiento. Una mirada unitaria desde la idea de vinculación contractual 'garantía"', en (Álvaro Vidal Olivares, Director) Estudios de Derecho de Contratos en homenaje a Antonio Manuel Morales Moreno (Chile, Editorial Legal Publishing) pp. 447-474.

V.AA. (2014): "Propósito práctico, incumplimiento contractual y remedios del acreedor. Con ocasión de tres recientes sentencias de la Corte Suprema", Ius et Praxis, Año 20, № 1, pp. 15-38.

W.AA. (2017): Los Principios Latinoamericanos de Derecho de los Contratos (Madrid, España, Boletín Oficial del Estado).

\section{NORMAS CITADAs.}

Código Civil de Chile.

Código Civil de Francia.

Código Civil y de Comercio de Argentina.

Convención de Viena sobre compraventa internacional de mercaderías.

\section{JURISPRUDENCIA CITADA.}

Ingeniería Eléctrica y Construcción Ltda. con Sociedad Austral de Electricidad S.A. (2016): Corte Suprema, 27 de septiembre de 2016 (recurso de casación en el fondo). Disponible en: https://app.vlex.com/\#CL/ search/jurisdiction:CL/INELCO+SAESA/CL/vid/650600453 [Fecha de consulta: 29.04.2019]. 